\title{
Epidemiology and Genetic Diversity of Rotavirus in Kunming, China, in 2015
}

\author{
Yongbo Kang ${ }^{\text {a-d }}$ Yue Cai ${ }^{b, d}$ \\ ${ }^{a}$ School of Basic Medical Sciences, Shanxi Medical University, Taiyuan, China; bedical Faculty, Kunming University \\ of Science and Technology, Kunming, China; ' Genetics and Pharmacogenomics Laboratory, Kunming University of \\ Science and Technology, Kunming, China; ${ }^{d}$ First People's Hospital of Yunnan, Kunming, China
}

\section{Keywords}

Rotavirus · Diarrhea · G and P types · Epidemiology

\begin{abstract}
Group A rotavirus (RVA) is a serious public problem in China, with a prevalence of $29.7 \%$ in diarrhea cases under 5 years of age. A total of 1,224 fecal specimens were collected in 2015 from children under 5 years of age with acute gastroenteritis in Kunming, China, for detection and characterization of rotavirus. The prevalence of RVA was $28.5 \%$. The frequency of RVA detection was greatest (52\%) among children aged 7-12 months. The following strains were the most common types: G9P(8) (58.2\%), G3P(8) (14.9\%), and G1P(8) (6.9\%). The following strains were uncommon types: G3P(4), G8P(9), and G9P(4) (1.1\%); G1P(4), G2P(8), and G4P(8) (0.9\%); G2P(6), $\mathrm{G3P}(9), \mathrm{G} 4 \mathrm{P}(6)$, and G9P(6) (0.6\%); and G4P(4) $(0.3 \%)$. G3G1P(8) (5.2\%), G1G2P(4) (0.9\%), G1G9P(8) (0.6\%), and $\mathrm{G} 2 \mathrm{P}(4) \mathrm{P}(8)(0.3 \%)$ were mixed types. This study documents the molecular epidemiology, genetics, and diversity of rotavirus strains in children under 5 years of age in Kunming, China, and suggests that it may be important to offer RVA vaccination and scientific evidence to stop and control RVArelated diarrhea.

(c) 2018 S. Karger AG, Basel
\end{abstract}

(c) 2018 S. Karger AG, Basel

\section{Introduction}

Acute gastroenteritis is a significant cause of morbidity and mortality in infants and young children under 5 years of age worldwide. It has caused 1.7 billion diarrhea episodes and over 700,000 childhood deaths [1]. In a variety of investigations, attempts were made to estimate the burden of bacterial, parasitic, and viral agents responsible for episodes of diarrhea in a group of children [2]. It was determined that, globally, rotavirus remains a major cause of morbidity and mortality in developing countries [3]. Rotaviruses belong to the family Reoviridae and are classified into 7 antigenic groups (A to $G$ ), of which groups A, B, and C are known to infect humans [4]. Group A rotaviruses (RVA) infect all children in their first few years of life and account for the vast majority of rotavirus infections worldwide, while $\mathrm{B}$ and $\mathrm{C}$ rotaviruses are often found to be associated with outbreaks and sporadic cases [4]. RVA-related diarrhea was ubiquitous; RVA infects almost all children, leading to 9.8 million severe diarrhea episodes and 193,000 child deaths worldwide every year.

Both authors contributed equally to this work.

\section{KARGER}

E-Mail karger@karger.com

www.karger.com/int
Yongbo Kang, $\mathrm{PhD}$

Medical Faculty, Kunming University of Science and Technology

No. 727 South Jingming Rd., Chenggong District

Kunming, Yunnan 650500 (China)

E-Mail657151276@qq.com; y.kang@ kmust.edu.cn 
It has been estimated that, worldwide, each year, RVAassociated diarrhea results in 9.8 thousand deaths in children aged less than 5 years, which account for $27 \%$ of all diarrhea-associated deaths and 3.0\% of all childhood deaths [1]. The importance of the pathogen has prompted extensive research on the structure and replication of the virus as well as the pathogenesis and the immune responses $[5,6]$. Rotavirus infections range from subclinical infection to severe gastroenteritis with diarrhea, vomiting, and lethal dehydration [3]. The major protective immune response against rotavirus is directed against the 2 outer capsid proteins VP7, a glycoprotein (G protein), and VP4, a protease-sensitive protein (P protein). Both proteins are used to type strains, which have been shown to vary over time within geographic locations and from region to region [3]. Molecular epidemiological studies have distinguished $27 \mathrm{G}$ genotypes and $35 \mathrm{P}$ genotypes. Of major worldwide epidemiological importance are the genotypes $\mathrm{G} 1 \mathrm{P}(8), \mathrm{G} 2 \mathrm{P}(4), \mathrm{G} 3 \mathrm{P}(8), \mathrm{G} 4 \mathrm{P}(8)$, and $\mathrm{G} 9 \mathrm{P}(8)$ and, to a lesser extent, G12P(8) [7].

The prevalence of RVA in children with gastroenteritis is $29.7 \%$ in China, and it is the most commonly identified enteral causative agent in acute gastroenteritis patients [8]. At present, data of RVA-related diarrhea is very limited in developing region such Yunnan Province, China. Furthermore, the molecular epidemiological characteristics of RVA are not clear. The aim of this study was to investigate the RVA disease burden and RVA epidemiological characteristics and genotypes in children aged $<5$ years from Kunming, China. The results of this study might be a pivotal reference for introduction of RVA vaccination to decrease the RVA-related disease burden.

\section{Materials and Methods}

\section{Specimens}

From January 2015 to December 2015, stool specimens were collected from children aged $<5$ years hospitalized for acute diarrhea in 3 different hospitals in Kunming, China (i.e., First People's Hospital of Yunnan Province, Children's Hospital of Kunming City, and Kunming City Maternal and Child Health Hospital). In the present study, acute gastroenteritis was defined as the passage of $\geq 3$ abnormal stools (e.g., watery, liquid, mucous, or bloody stool) a day with or without associated symptoms such as vomiting, fever, and abdominal pain. Stool specimens $(n=1,224)$ were obtained from acute gastroenteritis patients and then each stool sample was kept frozen at $-80^{\circ} \mathrm{C}$, transported to the laboratory on wet ice, and stored at $-80^{\circ} \mathrm{C}$ until further analysis. Epidemiologic data including age, dates of diarrhea onset, and specimen collection were available for the majority of the patients. The method employed for specimen collection was approved by the institutional human ethics committee.
Rotavirus Antigen Detection

Suspensions $(10 \%, \mathrm{w} / \mathrm{v})$ of each stool specimen prepared in $0.01 \mathrm{M}$ phosphate-buffered saline ( $\mathrm{pH}$ 7.2) were tested for RVA antigen by enzyme-linked immunosorbent assay (ELISA) using an Oxoid ProSpecT Rotavirus Microplate Assay (Oxoid Ltd., Hampshire, UK) as per the manufacturer's instructions.

\section{RNA Extraction}

Rotavirus dsRNA was extracted from $10 \%(\mathrm{w} / \mathrm{v})$ suspensions of all ELISA-positive stool specimens using TRIzol reagent (Invitrogen, Carlsbad, CA, USA) as per the manufacturer's protocol.

\section{$G$ and $P$ Genotyping}

The VP7 andVP4 genes were genotyped by multiplex reverse transcription (RT)-PCR according to the method described earlier with minor modifications in the thermal cycling program [4]. The viral RNA was subjected to 1-step RT-PCR (Qiagen, Hilden, Germany) using the outer primers 9Con1-L/VP7-R deg [9] and Con 3/ Con 2 [10] and oligonucleotide primers that could amplify the VP7 genotypes $\mathrm{G} 1$ to G4, G8 to G10, and G12 and the VP4 genotypes $\mathrm{P}(4), \mathrm{P}(6), \mathrm{P}(8), \mathrm{P}(9), \mathrm{P}(10)$, and $\mathrm{P}(11)$. Briefly, $4 \mu \mathrm{L}$ of dsRNA was denatured at $95^{\circ} \mathrm{C}$ for $5 \mathrm{~min}$ and then chilled in ice for $2 \mathrm{~min}$. A reaction mix of $46 \mu \mathrm{L}$ containing $5 \times$ buffer, dNTPs, RNase-free water, the primers 9Con1-L/Con3 and VP7-Rdeg/Con2, and $2 \mu \mathrm{L}$ of enzyme mix was added to make a final volume of $50 \mu \mathrm{L}$. The reaction tubes were placed in a thermocycler for $30 \mathrm{~min}$ at 45 and $95^{\circ} \mathrm{C}$ for $15 \mathrm{~min}$, followed by 40 cycles of $94^{\circ} \mathrm{C}$ for $1 \mathrm{~min}, 50^{\circ} \mathrm{C}$ for $1 \mathrm{~min}$, and $70^{\circ} \mathrm{C}$ for $2.5 \mathrm{~min}$, with a final extension at $70^{\circ} \mathrm{C}$ for $7 \mathrm{~min}$. All PCR products were analyzed by electrophoresis using Tris acetate EDTA buffer ( $\mathrm{pH} 8.3$ ) on $2 \%$ agarose gel containing ethidium bromide $(0.5 \mu \mathrm{g} / \mathrm{mL})$ and visualized under UV illumination.

\section{Statistical Analysis}

Data analysis was performed with SPSS 19.0 (IBM, USA); OR and $95 \%$ CI for categorical variables were calculated with the $\chi^{2}$ test, and medians and means of quantitative variables were analyzed using the $t$ test. Statistical methods was applied according to the characteristics of the data. $p<0.05$ was considered statistically significant.

\section{Results}

\section{Prevalence of RVA in Diarrhea Cases}

We collected a total of 1,224 stool specimens from children hospitalized for acute gastroenteritis during January 2015 to December 2015 in Kunming, China. Of these, 349 $(28.5 \%)$ were positive for rotavirus antigen by ELISA. The mean age $( \pm \mathrm{SD})$ of the children with diarrhea was $15.2 \pm$ 12.5 months. The mean age of the rotavirus-infected children was $11.6 \pm 7$ months, which was significantly lower $(p<0.01)$ than that of the rotavirus-uninfected children (i.e., $16.6 \pm 14.2$ months).

Diarrhea cases were further classified into the following 4 age groups: $0-6$ months ( $n=438 ; 35.8 \%), 7-12$ months ( $n=479 ; 38.1 \%), 13-24$ months $(n=165 ; 13.5 \%)$, and $25-$ 60 months $(n=142 ; 11.6 \%)$. The prevalence of RVA was
Kang/Cai 
Table 1. Age distribution of rotavirus positivity in children with acute gastroenteritis in Kunming, China

\begin{tabular}{lllllll}
\hline & Age group & & $\chi^{2}$ & $p$ value \\
\cline { 2 - 5 } & $\begin{array}{l}\text { 0-6 months } \\
(n=438)\end{array}$ & $\begin{array}{l}7-12 \text { months } \\
(n=479)\end{array}$ & $\begin{array}{l}13-24 \text { months } \\
(n=165)\end{array}$ & $\begin{array}{l}25-60 \text { months } \\
(n=142)\end{array}$ & & \\
\hline $\begin{array}{l}\text { Children infected } \\
\text { with RVA, } n(\%)\end{array}$ & $105(24.0)$ & $182(38.0)$ & $35(21.2)$ & $27(19.0)$ & 35.96 & 0.000 \\
\hline
\end{tabular}

significantly different among these 4 groups $\left(\chi^{2}=35.96\right.$, $p=0.000)$; the age group with the highest RVA detection rate was 7-12 months $(38.0 \%, 182 / 479)$, followed by $0-6$ months $(24.0 \%, 105 / 438), 13-24$ months (21.2\%, 35/165), and 25-60 months (19.0\%, 27/142) (Table 1).

\section{Common Genotypes among Diarrhea Cases}

Among the 349 rotavirus-infected children identified by RT-PCR from the diarrhea cases, 16 (4.6\%) were partially typed. In 7 samples the $\mathrm{P}$ genotype was identified but the G genotype was still not distinguished, and in 9 RVA specimens the $G$ genotype was defined but $P$ genotype remained negative; 333 (95.4\%) samples were identified to have both $\mathrm{G}$ and $\mathrm{P}$ genotypes. G9P(8) strains had the highest score (58.2\%), followed by: G3P(8) (14.9\%); G1P(8) (6.9\%); G3G1P(8) (5.2\%); G3P(4), G8P(9), and G9P(4) (1.1\%); G1P(4), G2P(8), G4P(8), and G1G2P(4) (0.9\%); G2P(6), G3P(9), G4P(6), G9P(6), and G1G9P(8) $(0.6 \%)$; and $\mathrm{G} 4 \mathrm{P}(4)$ and $\mathrm{G} 2 \mathrm{P}(4) \mathrm{P}(8)(0.3 \%)$ (Table 2). These data suggested that G9P(8) strains are prevalent among children infected with RVA in Kunming, China.

\section{RVA and Common Genotype Distribution by Age in \\ Diarrhea Cases}

Among the rotavirus-infected children, 105 (30\%) were in the age group of $0-6$ months, 182 (52\%) were in the age group of 7-12 months, 35(10\%) were in the age group of 13-24 months, and 27(8\%) were in the age group of 25-60 months. The proportion of each genotype was not very different in the four age groups, expect for G1P(4), which was more detected in diarrhea cases in the age group 13-24 months (Table 3).

\section{Discussion}

RVA is a serious public health problem in China, with a prevalence of $29.7 \%$ in diarrhea cases under 5 years of age [8]. The aim of this study was to describe the epide-
Table 2. Distribution of $G$ and $P$ type rotavirus strains in children with acute gastroenteritis in Kunming, China

\begin{tabular}{lc}
\hline G and P types & $\begin{array}{c}\text { Age group } 0-60 \text { months } \\
(n=349)\end{array}$ \\
\hline Common types (total) & $279(79.9)$ \\
G1P(8) & $24(6.9)$ \\
G3P(8) & $52(14.9)$ \\
G9P(8) & $203(58.2)$ \\
Uncommon types (total) & $30(8.6)$ \\
G1P(4) & $3(0.9)$ \\
G2P(6) & $2(0.6)$ \\
G2P(8) & $3(0.9)$ \\
G3P(4) & $4(1.1)$ \\
G3P(9) & $2(0.6)$ \\
G4P(4) & $1(0.3)$ \\
G4P(6) & $2(0.6)$ \\
G4P(8) & $3(0.9)$ \\
G8P(9) & $4(1.1)$ \\
G9P(4) & $4(1.1)$ \\
G9P(6) & $2(0.6)$ \\
Mixed types (total) & $24(6.9)$ \\
G1G2P(4) & $3(0.9)$ \\
G1G9P(8) & $2(0.6)$ \\
G2P(4)P(8) & $1(0.3)$ \\
G3G1P(8) & $18(5.2)$ \\
G/P untyped & $16(4.6)$ \\
\hline
\end{tabular}

Values are presented as $n(\%)$.

miologic feature of RVA and the RVA-related disease burden among acute gastroenteritis patients under 5 years of age in Kunming, China, in 2015. The prevalence of RVA (28.5\%) in this study was approximately equal to that in a 5-year surveillance study conducted in China (29.7\%) [8], but the prevalence of RVA in this study was higher than those in other studies conducted in developed countries such Japan, Belgium, and Italy $(11.9,6.4$, and $2.6 \%$, respectively), where the RVA vaccine has been introduced in national immunization programs [11-13]. The prevalence of RVA is still as high as $34.0 \%$ in diarrhea 
Table 3. Age distribution of $G$ and $P$ type rotavirus strains in children with acute gastroenteritis in Kunming, China

\begin{tabular}{|c|c|c|c|c|c|c|}
\hline \multirow[t]{2}{*}{$\mathrm{G}$ and $\mathrm{P}$ types } & \multicolumn{4}{|l|}{ Age group } & \multirow[t]{2}{*}{$\chi^{2}$} & \multirow[t]{2}{*}{$p$ value } \\
\hline & $\begin{array}{l}0-6 \text { months } \\
(n=105)\end{array}$ & $\begin{array}{l}7-12 \text { months } \\
(n=182)\end{array}$ & $\begin{array}{l}13-24 \text { months } \\
(n=35)\end{array}$ & $\begin{array}{l}25-60 \text { months } \\
(n=27)\end{array}$ & & \\
\hline Common types (total) & $88(83.8)$ & $149(81.9)$ & $21(60.0)$ & $21(77.8)$ & 8.82 & 0.032 \\
\hline $\mathrm{G} 1 \mathrm{P}(8)$ & $11(10.5)$ & $7(3.8)$ & $2(5.7)$ & $4(14.8)$ & 7.04 & 0.071 \\
\hline G3P(8) & $19(18.1)$ & $25(13.7)$ & $4(11.4)$ & $4(14.8)$ & 1.37 & 0.716 \\
\hline G9P(8) & $58(55.2)$ & $117(64.3)$ & $15(42.9)$ & $13(48.1)$ & 7.62 & 0.054 \\
\hline Uncommon types (total) & $7(6.7)$ & $13(7.1)$ & $7(20.0)$ & $3(11.1)$ & 5.61 & 0.132 \\
\hline $\mathrm{G} 1 \mathrm{P}(4)$ & $1(1.0)$ & $0(0.0)$ & $2(5.7)$ & $0(0.0)$ & 7.88 & 0.049 \\
\hline G2P(6) & $0(0.0)$ & $1(0.5)$ & $1(2.9)$ & $0(0.0)$ & 5.61 & 0.132 \\
\hline G2P(8) & $2(1.9)$ & $1(0.5)$ & $0(0.0)$ & $0(0.0)$ & 2.31 & 0.511 \\
\hline G3P(4) & $0(0.0)$ & $3(1.6)$ & $0(0.0)$ & $1(3.7)$ & 4.57 & 0.206 \\
\hline G3P(9) & $0(0.0)$ & $2(1.1)$ & $0(0.0)$ & $0(0.0)$ & 2.62 & 0.455 \\
\hline G4P(4) & $1(1.0)$ & $0(0.0)$ & $0(0.0)$ & $0(0.0)$ & 2.41 & 0.492 \\
\hline G4P(6) & $1(1.0)$ & $1(0.5)$ & $0(0.0)$ & $0(0.0)$ & 0.935 & 0.817 \\
\hline G4P(8) & $0(0.0)$ & $1(0.5)$ & $2(5.7)$ & $0(0.0)$ & 6.78 & 0.079 \\
\hline G8P(9) & $2(1.9)$ & $0(0.0)$ & $1(2.9)$ & $1(3.7)$ & 6.26 & 0.099 \\
\hline G9P(4) & $0(0.0)$ & $3(1.6)$ & $0(0.0)$ & $1(3.7)$ & 4.57 & 0.206 \\
\hline G9P(6) & $0(0.0)$ & $1(0.5)$ & $1(2.9)$ & $0(0.0)$ & 3.15 & 0.369 \\
\hline Mixed types (total) & $6(5.7)$ & $14(7.7)$ & $3(8.6)$ & $1(3.7)$ & 1.07 & 0.785 \\
\hline $\mathrm{G} 1 \mathrm{G} 2 \mathrm{P}(4)$ & $1(1.0)$ & $2(1.1)$ & $0(0.0)$ & $0(0.0)$ & 1.193 & 0.755 \\
\hline G1G9P(8) & $0(0.0)$ & $1(0.5)$ & $0(0.0)$ & $1(3.7)$ & 3.68 & 0.298 \\
\hline $\mathrm{G} 2 \mathrm{P}(4) \mathrm{P}(8)$ & $0(0.0)$ & $1(0.5)$ & $0(0.0)$ & $0(0.0)$ & 1.31 & 0.728 \\
\hline G3G1P(8) & $5(4.8)$ & $10(5.5)$ & $3(8.6)$ & $0(0.0)$ & 3.64 & 0.303 \\
\hline G/P untyped & $4(3.8)$ & $6(3.3)$ & $4(11.4)$ & $2(7.4)$ & 4.03 & 0.259 \\
\hline
\end{tabular}

Values are presented as $n(\%)$.

cases in low-income and middle-income countries, where RVA vaccination is not obtained. Hence, these data suggest that safe, effective, and affordable RVA vaccination is an effective way to reduce the numbers of RVA infections and RVA related deaths. Two rotavirus vaccines, i.e., Rotarix ${ }^{\mathrm{TM}}$ and RotaTeq ${ }^{\circledR}$, have been licensed in many countries, except for China, for use against rotavirus diarrhea. Both vaccines are recommended by the World Health Organization (WHO) in childhood immunization programs conducted globally [14]. Studies have reported difference in the efficacies of these vaccines against severe rotavirus diarrhea in high- and middle-income (85-98\%) and low-income (39-72\%) countries [15]. Although RVA vaccination has a low influence on the reduction of RVA-related diarrhea in developing countries, RVA variance can reduce obviously severe RVA-associated diarrhea and death worldwide. Rotavirus viral antigens VP7 and VP4 are considered important targets for vaccine development because they are immunogenic and elicit protective neutralizing antibodies [16]. However, considering RVA genotypes varied in terms of their spa- tial-temporal distribution, surveillance of $\mathrm{G}$ and $\mathrm{P}$ combination genotypes was an important reference factor for choosing and introducing RVA variance in the prevaccine era. We found that the rate of diarrhea cases among the 4 age groups was significantly different; the prevalence of RVA was $24.0 \%(105 / 438)$ in the age group of $0-6$ months, but it increased sharply to $38.0 \%(182 / 479)$ in the age group of 7-12 months, and then the detection rate of RVA declined continuously with increasing age. This conclusion was in keeping with previous studies [17-19]. We speculated that children under 6 months of age may obtain protective immunity against RVA. There are 2 hypotheses that can explain the phenomenon. One hypothesis is that children under 6 months of age can stop RVA infection by IgG acquired from the mother [20]. Another hypothesis is that breast milk has substantial IgA and other nonspecific immune factors such lactoferrin that can prevent RVA infection [20,21]. In addition, we observed that both $\mathrm{G}$ and $\mathrm{P}$ genotypes were identified in 333 (95.4\%) samples. G9P(8) (58.2\%) had predominantly a G and $\mathrm{P}$ combination, and the total proportion of $\mathrm{G} 9 \mathrm{P}(8)$,
12

Intervirology 2018;61:9-13 DOI: $10.1159 / 000489309$
Kang/Cai 
G3P(8), and G1P(8) being as high as $79.9 \%$ in all RVA strains in this study. A similar conclusion was obtained in other study [17]. In addition, the proportion of each genotype was not very different in several age groups, expect for G1P(4), which was more detected in diarrhea cases in the age group of 13-24 months.

In conclusion, our study demonstrated the epidemiological characteristics and genetic (G/P genotypes) diversity of RVA in Kunming, China, before introduction of the RVA vaccine. These data are significant, suggest the need to introduce the RVA vaccine, and provide scientific evidence to stop and control RVA-related diarrhea.

\section{Acknowledgement}

We sincerely thank the staffs in there 3 hospitals (First People's Hospital of Yunnan Province, Children's Hospital of Kunming City, and Kunming City Maternal and Child Health Hospital) for collection of the stool specimens and investigation of the epidemiological information.

\section{Disclosure Statement}

The authors have no conflict of interests to declare.

\section{References}

1 Walker CL, Rudan I, Liu L, et al: Global burden of childhood pneumonia and diarrhoea. Lancet 2013;381:1405.

2 Ahmed SM, Hall AJ, Robinson AE, et al: Global prevalence of norovirus in cases of gastroenteritis: a systematic review and metaanalysis. Lancet Infect Dis 2014;14:725-730.

3 Baqlani SA: Molecular Characterization of Group A Rotavirus Genotypes Circulating in Oman between 2009 and 2013. J Emerg Dis Virol 2016;2:2.

4 Tatte VS, Gentsch JR, Chitambar SD: Characterization of group A rotavirus infections in adolescents and adults from Pune, India: 1993-1996 and 2004-2007. J Med Virol 2010; 82:519-527.

5 Patton JT: Rotavirus diversity and evolution in the post-vaccine world. Discov Med 2012; 13:85-97.

6 Desselberger U: Rotaviruses. Virus Res 2014; 190:75-96.

7 Matthijnssens J, Van RM: Genotype constellation and evolution of group A rotaviruses infecting humans. Curr Opin Virol 2012;2: 426.

8 Yu J, Jing H, Lai S, et al: Etiology of diarrhea among children under the age five in China: results from a five-year surveillance. J Infect 2015;71:19-27.
9 Freeman MM, Kerin T, Hull J, et al: Enhancement of detection and quantification of rotavirus in stool using a modified real-time RTPCR assay. J Med Virol 2008;80:1489-1496.

10 Gentsch JR, Glass RI, Woods P, et al: Identification of group A rotavirus gene 4 types by polymerase chain reaction. J Clin Microbiol 1992;30:1365-1373.

11 Ianiro G, Delogu R, Bonomo P, et al: Molecular analysis of group A rotaviruses detected in adults and adolescents with severe acute gastroenteritis in Italy in 2012. J Med Virol 2014; 86:1073-1082.

12 Tajiri $\mathrm{H}$, Takeuchi $\mathrm{Y}$, Takano $\mathrm{T}$, et al: The burden of rotavirus gastroenteritis and hospitalacquired rotavirus gastroenteritis among children aged less than 6 years in Japan: a retrospective, multicenter epidemiological survey. BMC Pediatr 2013;13:83.

13 Zeller M, Rahman M, Heylen E, et al: Rotavirus incidence and genotype distribution before and after national rotavirus vaccine introduction in Belgium. Vaccine 2010;28:7507.

14 English AI: Meeting of the immunization Strategic Advisory Group of Experts, November 2008: conclusions and recommendations. Wkly Epidemiol Rec 2009;84:220.
15 Dennehy PH: Rotavirus vaccines: an overview. Clin Microbiol Rev 2008;21:198-208.

16 Khamrin P, Maneekarn N, Peerakome S, et al: Novel porcine rotavirus of genotype $\mathrm{P}$ [27] shares new phylogenetic lineage with G2 porcine rotavirus strain. Virology 2007;361:243252.

17 Zhang S, Yin J, Yang J, et al: Epidemiology and genetic diversity of group A rotavirus in acute diarrhea patients in pre-vaccination era in southwest China. J Med Virol 2016;89:71-78.

18 Duan ZJ, Liu N, Yang SH, et al: Hospitalbased surveillance of rotavirus diarrhea in the People's Republic of China, August 2003-July 2007. J Infect Dis 2009;200(suppl 1):S167S173.

19 Salim H, Karyana IPG, Sanjaya-Putra IGN, et al: Risk factors of rotavirus diarrhea in hospitalized children in Sanglah Hospital, Denpasar: a prospective cohort study. BMC Gastroenterol 2014;14:1-6.

20 Levine MM, Robins-Browne RM: Factors that explain excretion of enteric pathogens by persons without diarrhea. Clin Infect Dis 2012; 55:S303-S311.

21 Morrow AL, Ruiz-Palacios GM, Jiang X, et al: Human-milk glycans that inhibit pathogen binding protect breast-feeding infants against infectious diarrhea. J Nutr 2005; 135:13041307 